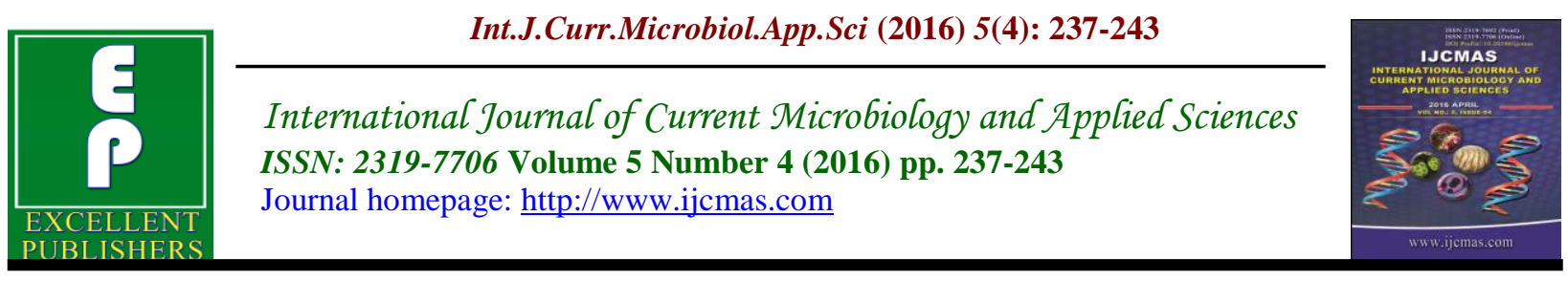

Original Research Article

http://dx.doi.org/10.20546/ijcmas.2016.504.029

\title{
Antibacterial Screening of Leaf and Bark extracts of Holarrhena antidysenterica (L.) Wall
}

\author{
Preeti Kaundal* and Anand Sagar \\ Department of Biosciences, Himachal Pradesh University, Shimla-5 (H.P.) India \\ *Corresponding author
}

Keywords

Holarrhena antidysenterica, Antibacterial activity,

Methanol and Acetone extracts.

\section{Article Info}

Accepted:

15 March 2016 Available Online: 10 April 2016

\section{A B S T R A C T}

The present study aims to determine antibacterial activity of acetone and methanol extracts from leaves and bark of Holarrhena antidysenterica. Agar well diffusion method was used for screening of extracts against six bacteria using different concentrations (25, 50, 75 and 100\%) of extracts. Methanol and acetone extracts of both leaves and bark showed potent antibacterial activity against all six tested bacteria. Extracts prepared using methanol exhibited higher antibacterial activity as compared to its corresponding acetone extract. In general trend growth inhibition was found to be higher for $S$. aureus and B. Cereus followed by E. coli, L. monocytogenes, P. aeruginosa and $Y$. pestis. Bark extracts (methanol and acetone) were more active towards all the bacterial strains as compare to leaves extracts as only methanolic leaves extracts showed considerable inhibition zone.

\section{Introduction}

The use of plants and plant products as medicines could be traced from the beginning of human civilization. The earliest mention of plants as medicine in Hindu culture is found in 'Rigveda', which is written between 4500-1600 B.C (Rastogi and Mehrotra, 2002). Medicinal plants are a source of great economic value all over the world. A major part of the total population in developing countries still uses traditional folk medicine obtained from plant resources (Farnsworth, 1994).

The beneficial medicinal effects of plant materials result from the combinations of secondary products present in the plant. In plants, these compounds are mostly secondary metabolites such as alkaloids, tannins, and phenolic compounds, flavonoids, resins, fatty acids and gums which produce definite physiological action on body (Saranraj and Sivasakthi, 2014). The use of plant extracts and photochemicals, with known reliable antimicrobial and antioxidant efficiencies can be of great significance in treatment of many diseases (Lewis and Lewis, 1997). Antimicrobials originated from plants are 
effective in the treatment of various infectious diseases while simultaneously alleviate many of the side effects which are often associated with synthetic antimicrobials (Prumal and Ignacimuthu, 2000). In order to promote the use of medicinal plants as potential sources of antimicrobial compounds, it is relevant to thoroughly investigate their activity to validate their use (Nair and Chanda, 2006).

Holarhena antidysenterica, commonly called as Conessi or Tellichery Bark belongs to family Apocynaceae. It is locally called as Keor or Inderjau in Himachal Pradesh. $H$. antidysenterica is a glabrous, deciduous, shrub or 3- $4.5 \mathrm{~m}$ high tree. Leaves are subsessile or sessile, opposite, ovate-oblong or elliptic. Bark is rough, dark, pale brown or purplish, exfoliating in irregular flakes. Flowers are white, inodorous and arranged in terminal corymbose cymes. Flowering occurs in May-July. Fruits are follicles which are cylindrical. Seeds are linearoblong and are tipped with a spreading deciduous coma of hair. Bark is antidiarrhoeal and antidysentric and used in fevers, piles, leprosy, diseases of skin and spleen, dysentery and diarrhoea. Leaves are used to cure ulcers, wounds, muscles pain, and menstrual problems (Kritikar and Basu, 1984). Distribution: Tropical South and South East Asia, Africa, India, Pakistan, Myanmar, Indo- China.

\section{Materials and Methods}

\section{Material Collection}

The plant leaves and bark were collected from Distt. Kangra, Himachal Pradesh. The plant was identified at Department of Biosciences, Himachal Pradesh University, Shimla. The leaves and bark were thoroughly cleaned and were dried. The dried leaves and bark were weighed and ground to fine powder.

\section{Test Organisms}

Three gram positive bacteria i.e Listeria monocytogenes, Bacillus cereus, Staphylococcus aureus and three gram negative bacteria i.e Escherichia coli, Pseudomonas aeruginosa and Yersinia pestis were used in the present study. All the bacteria used were obtained from Department of Microbiology, IGMC, Shimla.

\section{Preparation of Plant Extracts}

The dried leaves and bark (50 g) of $H$. antidysenterica was soaked separately in $300 \mathrm{ml}$ of methanol and acetone in Erlenmeyer flask for methanol and acetone extracts. The flasks were covered with aluminium foil and allowed to stand for 7 days for extraction. These extracts were filtered through Whatman filter paper no. 1 and evaporated at $40^{\circ} \mathrm{C}$ using rotary evaporator (Jonathan and Fasidi, 2003; Balakumar et al., 2011).The extracts were collected and stock solution of conc. 10 $\mathrm{mg} / \mathrm{ml}$ was prepared for further antibacterial screening process.

\section{Screening of Plant Extracts for Antibacterial Activity}

Screening of plants extracts (methanol and acetone) was done using agar well diffusion method. Nutrient agar medium (Beef extract 1g, Yeast extract 2g, Sodium Chloride 1g, Peptone 5g, Agar 20g, Distilled Water $1000 \mathrm{ml}$ ) was used throughout the investigation. The medium was autoclaved at $121.6^{\circ} \mathrm{C}$ for 30 minutes and poured into Petri plates. Bacteria were grown in nutrient broth for 24 hours. A $100 \mu \mathrm{l}$ of bacterial suspension was spread on each nutrient agar plates. Five agar wells of $8 \mathrm{~mm}$ diameter were prepared with the help of sterilized stainless steel cork borer in each Petri plate. 
The wells in each plate were loaded with $25 \%, 50 \%, 75 \%$ and $100 \%$ concentration of prepared extracts of collected plant material. The control well contains pure solvent only. The plates were incubated at $37 \pm 20^{\circ} \mathrm{C}$ for 24 hours in the incubation chamber. The zone of growth inhibition was calculated by measuring the diameter of the inhibition zone around the well (in $\mathrm{mm}$ ) including the well diameter. The readings were taken in perpendicular direction in three replicates and the average values were tabulated (Hemashenpagam and Selvaraj, 2010).

\section{Results and Discussion}

In the present investigation leaves and bark extracts (methanol and acetone) of Holarrhena antidysenterica were evaluated for antibacterial activity. The methanolic and acetone extracts showed considerable growth inhibition of six tested bacteria in different concentrations $(25 \%, 50 \%, 75 \%$ and 100\%). Both extracts (leaves and bark) were seen to show gradual inhibition in the growth of bacterial strains. This inhibition increased with the increase in concentration of the extracts and reached its maximum at $100 \%$ conc. Control wells showed no inhibition against test bacteria. Stock solution of $10 \mathrm{mg} / \mathrm{ml}$ was considered as $100 \%$ conc. and other concentrations were prepared by serial dilution of stock solution. It is clear from Table 1 . and Fig. 1 that methanolic extract of $H$. antidysenterica bark gave inhibition zones of around 20.6 $\mathrm{mm}$ for Staphylococcus aureus, 19.3 for Bacillus cereus, $18.6 \mathrm{~mm}$ for Escherichia coli, 17.3 for Pseudomonas aeruginosa and $15.3 \mathrm{~mm}$ for Listeria monocytogenes. Similar trends were seen in case of acetone bark extract in which highest inhibition was seen for B. cereus $(17.2 \mathrm{~mm})$ and lowest inhibitions for $Y$. pestis $(13.6 \mathrm{~mm})$ (Table 2, Fig. 2). Methanolic leaves extracts showed highest inhibition zone for $S$. aureus (20.0 $\mathrm{mm}$ ) followed by $B$. cereus, Y. pestis, $E$. coli, L. monocytogenes and $P$. aeruginosa (Table 3, Fig. 3). Acetone extracts of leaves showed lowest inhibition zones and zones were mostly seen at $100 \%$ conc. (Table 4, Fig. 4). In general trend highest inhibition zones were shown against $S$. aureus $B$. cereus. Result obtained from present study revealed that both leaves and bark extracts of $H$. antidysentrica have shown considerable inhibition against gram positive and gram negative bacteria.

Table.1 Inhibition Zone Diameter (MM) of Bacteria at Different Concentrations of Methanolic Extract of Holarrhena Antidysenterica Bark

\begin{tabular}{|c|c|c|c|c|c|c|}
\hline \multirow{2}{*}{$\begin{array}{c}\text { Conc. } \\
(\%)\end{array}$} & B. cereus & $\begin{array}{l}\text { L.monocyt- } \\
\text { ogenes }\end{array}$ & S. aureus & E. coli & $\begin{array}{l}\text { P.aerugin- } \\
\text { osa }\end{array}$ & Y.pestis \\
\cline { 2 - 7 } & & $0.00 \pm 0.00$ & $0.00 \pm 0.00$ & $0.00 \pm 0.00$ & $0.00 \pm 0.00$ & $0.00 \pm 0.00$ \\
\hline Control & $0.00 \pm 0.00$ & $11.6 \pm 0.03$ & $14.6 \pm 0.01$ & $11.6 \pm 0.05$ & $11.0 \pm 0.00$ & $11.0 \pm 0.00$ \\
\hline 25 & $11.6 \pm 0.03$ & $12.6 \pm 0.05$ & $16.0 \pm 0.05$ & $13.3 \pm 0.06$ & $12.6 \pm 0.05$ & $12.6 \pm 0.05$ \\
\hline 50 & $12.3 \pm 0.05$ & $14.8 \pm 0.05$ & $17.6 \pm 0.05$ & $15.4 \pm 0.05$ & $13.3 \pm 0.15$ & $14.3 \pm 0.05$ \\
\hline 75 & $14.5 \pm 0.05$ & 14.05 & $15.3 \pm 0.25$ & $17.3 \pm 0.11$ \\
\hline 100 & $19.3 \pm 0.12$ & $16.3 \pm 0.15$ & $20.6 \pm 0.15$ & $18.6 \pm 0.15$ & 15.3 \\
\hline
\end{tabular}

Each data represents mean of three replicate \pm S.D 
Table.2 Inhibition Zone Diameter (MM) of Bacteria at Different Concentrations of Acetone Extract of Holarrhena antidysenterica Bark

\begin{tabular}{|c|c|c|c|c|c|c|}
\hline \multirow{2}{*}{$\begin{array}{c}\text { Conc. } \\
(\%)\end{array}$} & \multicolumn{6}{|c|}{ Inhibition zone diameter in (mm \pm S.D.) } \\
\cline { 2 - 7 } & B. cereus & $\begin{array}{l}\text { L.monocyt- } \\
\text { ogenes }\end{array}$ & S. aureus & E. coli & $\begin{array}{l}\text { P.aerugin- } \\
\text { osa }\end{array}$ & Y. pestis \\
\hline Control & $0.00 \pm 0.00$ & $0.00 \pm 0.00$ & $0.00 \pm 0.00$ & $0.00 \pm 0.00$ & $0.00 \pm 0.00$ & $0.00 \pm 0.00$ \\
\hline 25 & $12.0 \pm 0.00$ & $11.0 \pm 0.00$ & $11.0 \pm 0.00$ & $11.0 \pm 0.00$ & $11.0 \pm 0.00$ & $11.0 \pm 0.00$ \\
\hline 50 & $12.3 \pm 0.05$ & $11.6 \pm 0.01$ & $12.3 \pm 0.05$ & $11.3 \pm 0.05$ & $11.4 \pm 0.03$ & $11.3 \pm 0.05$ \\
\hline 75 & $13.6 \pm 0.15$ & $12.3 \pm 0.05$ & $13.3 \pm 0.01$ & $12.6 \pm 0.05$ & $12.3 \pm 0.05$ & $12.3 \pm 0.05$ \\
\hline 100 & $17.2 \pm 0.12$ & $14.3 \pm 0.10$ & $15.6 \pm 0.20$ & $15.3 \pm 0.05$ & $14.6 \pm 0.15$ & $13.6 \pm 0.15$ \\
\hline
\end{tabular}

Each data represents mean of three replicate \pm S.D

Table.3 Inhibition Zone Diameter (MM) of Bacteria at Different Concentrations of Methanolic Extract of Holarrhena antidysenterica Leaves

\begin{tabular}{|c|c|c|c|c|c|c|}
\hline \multirow[b]{2}{*}{$\begin{array}{c}\text { Conc. } \\
(\%)\end{array}$} & \multicolumn{6}{|c|}{ Inhibition zone diameter in $(\mathrm{mm} \pm$ S.D. $)$} \\
\hline & B. cereus & $\begin{array}{l}\text { L.monocyt- } \\
\text { ogenes }\end{array}$ & S. aureus & E. coli & $\begin{array}{l}\text { P.aerugin- } \\
\text { osa }\end{array}$ & Y.pestis \\
\hline Control & $0.00 \pm 0.00$ & $0.00 \pm 0.00$ & $0.00 \pm 0.00$ & $0.00 \pm 0.00$ & $0.00 \pm 0.00$ & $0.00 \pm 0.00$ \\
\hline 25 & $11.3 \pm 0.03$ & $11.3 \pm 0.05$ & $12.3 \pm 0.01$ & $11.3 \pm 0.05$ & $11.0 \pm 0.05$ & $12.3 \pm 0.05$ \\
\hline 50 & $14.0 \pm 0.05$ & $11.6 \pm 0.05$ & $14.3 \pm 0.05$ & $12.8 \pm 0.05$ & $11.3 \pm 0.05$ & $13.3 \pm 0.05$ \\
\hline 75 & $15.3 \pm 0.05$ & $13.3 \pm 0.05$ & $16.6 \pm 0.05$ & $14.3 \pm 0.05$ & $11.6 \pm 0.05$ & $14.8 \pm 0.05$ \\
\hline 100 & $18.3 \pm 0.05$ & $14.3 \pm 0.10$ & $20.0 \pm 0.20$ & $15.8 \pm 0.15$ & $12.6 \pm 0.11$ & $15.3 \pm 0.11$ \\
\hline
\end{tabular}

Each data represents mean of three replicate \pm S.D

Fig.1 Inhibition in the Growth of A) B. cereus, B) L. monocytogenes, C) S. aureus, D) E. coli, E) P.aeruginosa and F) $Y$. pestis at Different Concentrations of Methanol Bark Extract of Holarrhena antidysenterica
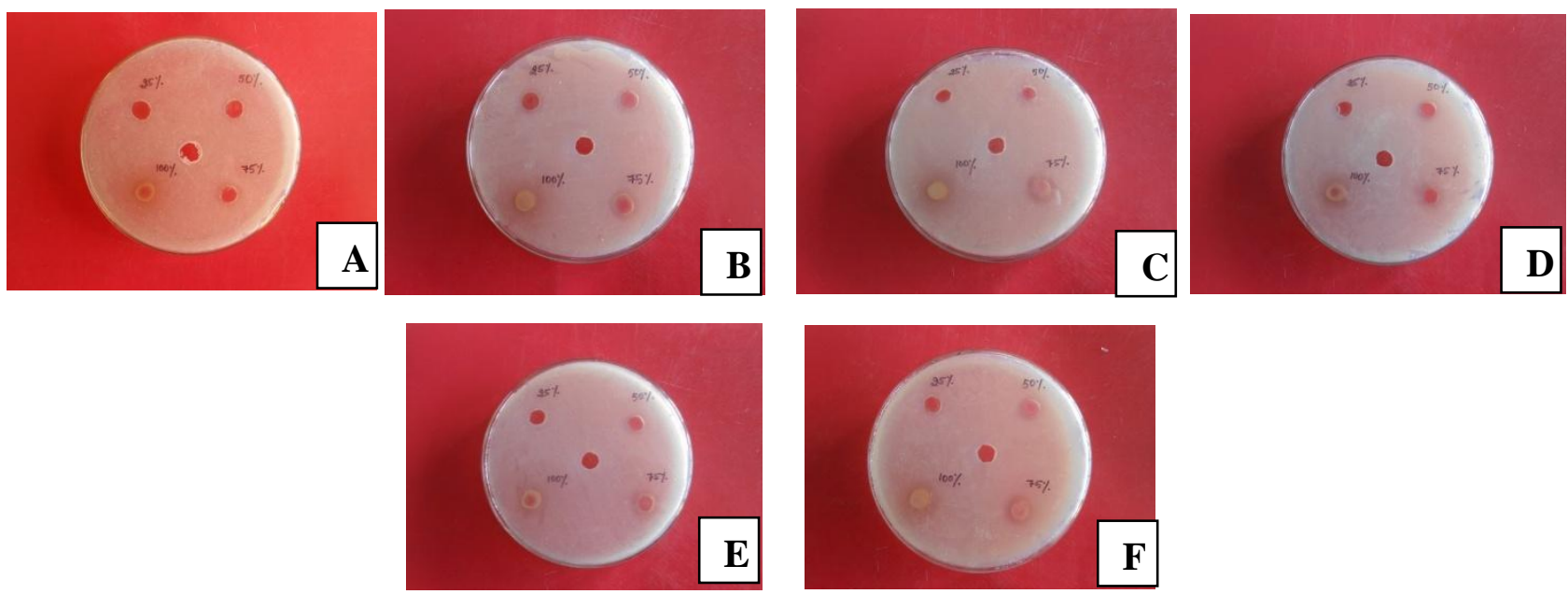
Fig.2 Inhibition in the Growth of A) B. cereus, B) L. monocytogenes, C) S. aureus, D) E. coli, E) P.aeruginos and F) Y. pestis at Different Concentrations of Acetone Bark Extract of Holarrhena antidysenterica
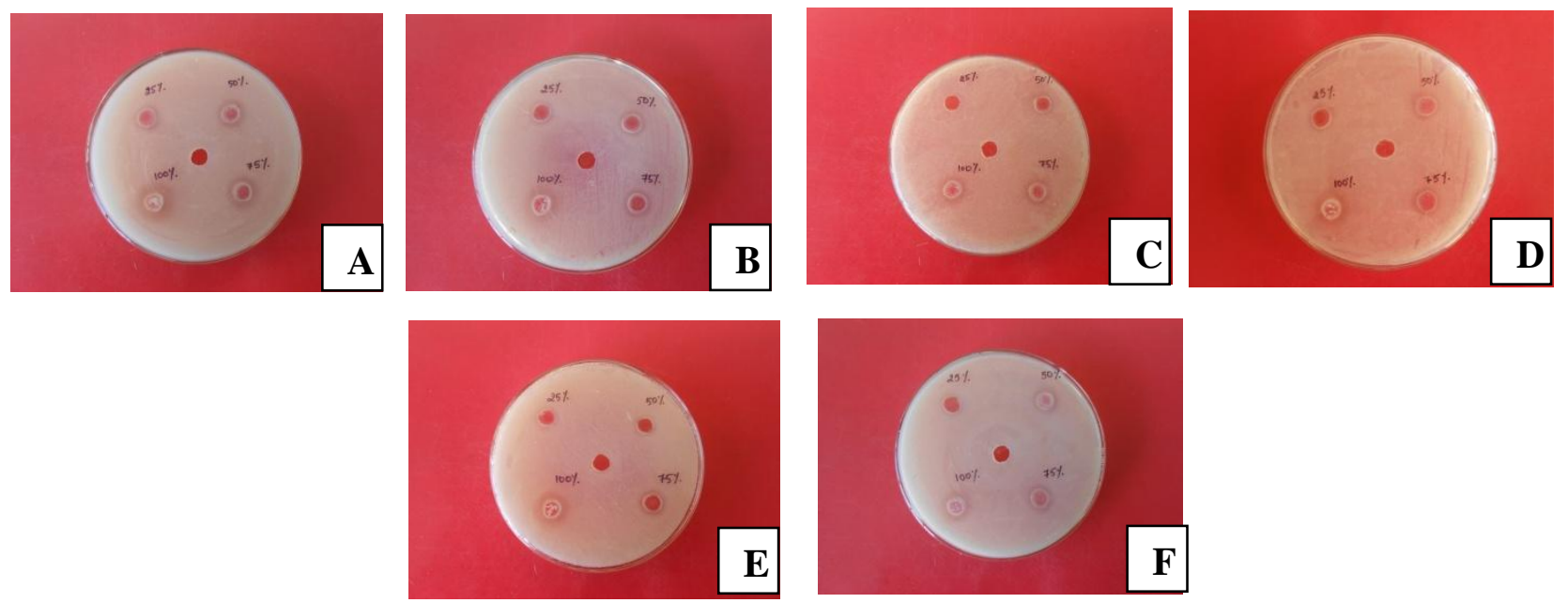

Fig.3 Inhibition in the Growth of A) B. cereus, B) L. monocytogenes, C) S. aureus, D) E. coli, E) P.aeruginosa and F) Y. pestis at Different Concentrations of Methanol Leaves Extract of Holarrhena antidysenterica
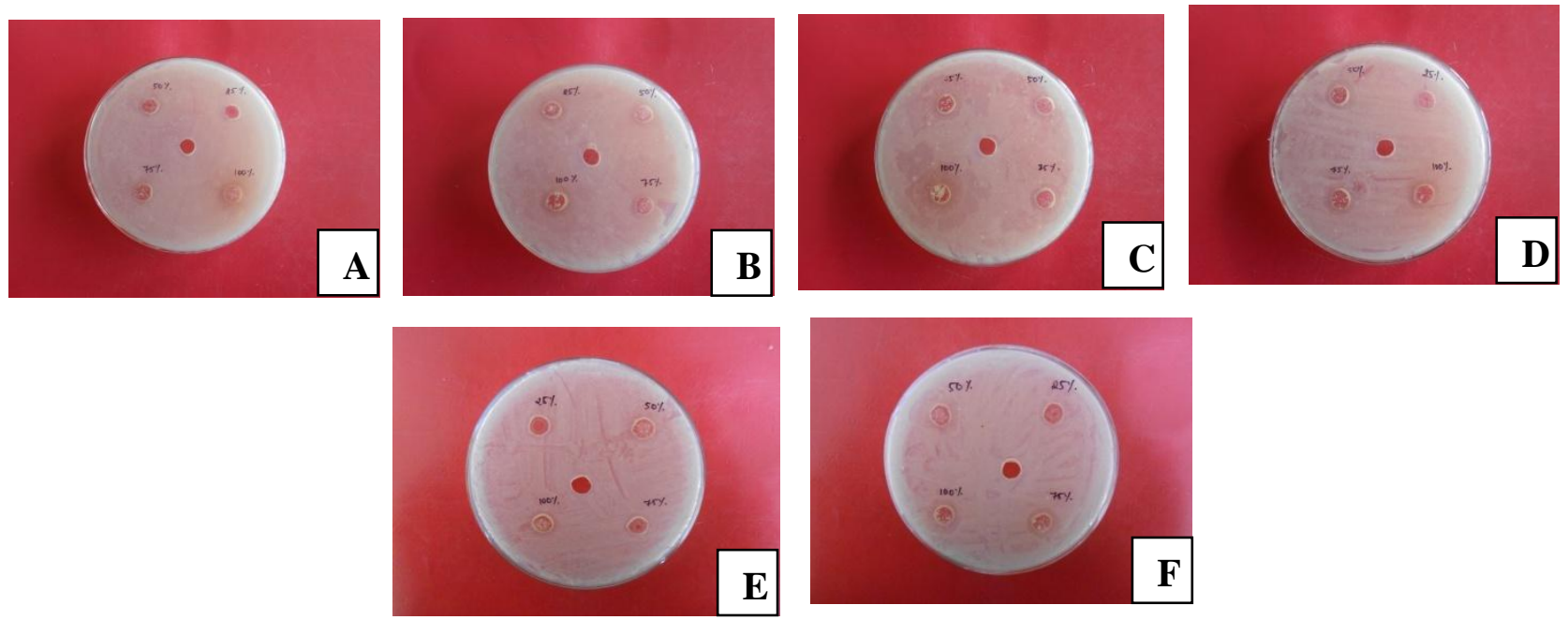
Table.4 Inhibition Zone Diameter (MM) of Bacteria at Different Concentrations of Acetone Extract of Holarrhena antidysenterica Leaves

\begin{tabular}{|c|c|c|c|c|c|c|}
\hline \multirow{2}{*}{$\begin{array}{c}\text { Conc. } \\
(\%)\end{array}$} & \multicolumn{6}{|c|}{ Inhibition zone diameter in (mm S.D.) } \\
\cline { 2 - 7 } & B. cereus & L.monocytogenes & S. aureus & E. coli & P.aeruginosa & Y.pestis \\
\hline Control & $0.00 \pm 0.00$ & $0.00 \pm 0.00$ & $0.00 \pm 0.00$ & $0.00 \pm 0.00$ & $0.00 \pm 0.00$ & $0.00 \pm 0.00$ \\
\hline 25 & - & - & - & - & - & - \\
\hline 50 & - & $11.3 \pm 0.01$ & $11.0 \pm 0.00$ & $11.3 \pm 0.01$ & - & - \\
\hline 75 & $12.6 \pm 0.05$ & $12.0 \pm 0.01$ & $13.3 \pm 0.01$ & $12.3 \pm 0.05$ & $11.3 \pm 0.01$ & $11.0 \pm 0.00$ \\
\hline 100 & $13.8 \pm 0.15$ & $13.6 \pm 0.05$ & $15.6 \pm 0.05$ & $13.3 \pm 0.01$ & $12.2 \pm 0.10$ & $12.3 \pm 0.05$ \\
\hline
\end{tabular}

Each data represents mean of three replicate \pm S.D

Fig4 Inhibition in the Growth of a) B. Cereus, b) L. Monocytogenes, c) S. Aureus, d) E. Coli, e) P.aeruginosa and f) Y. Pestis at Different Concentrations of Acetone Leaves Extract of Holarrhena Antidysenterica
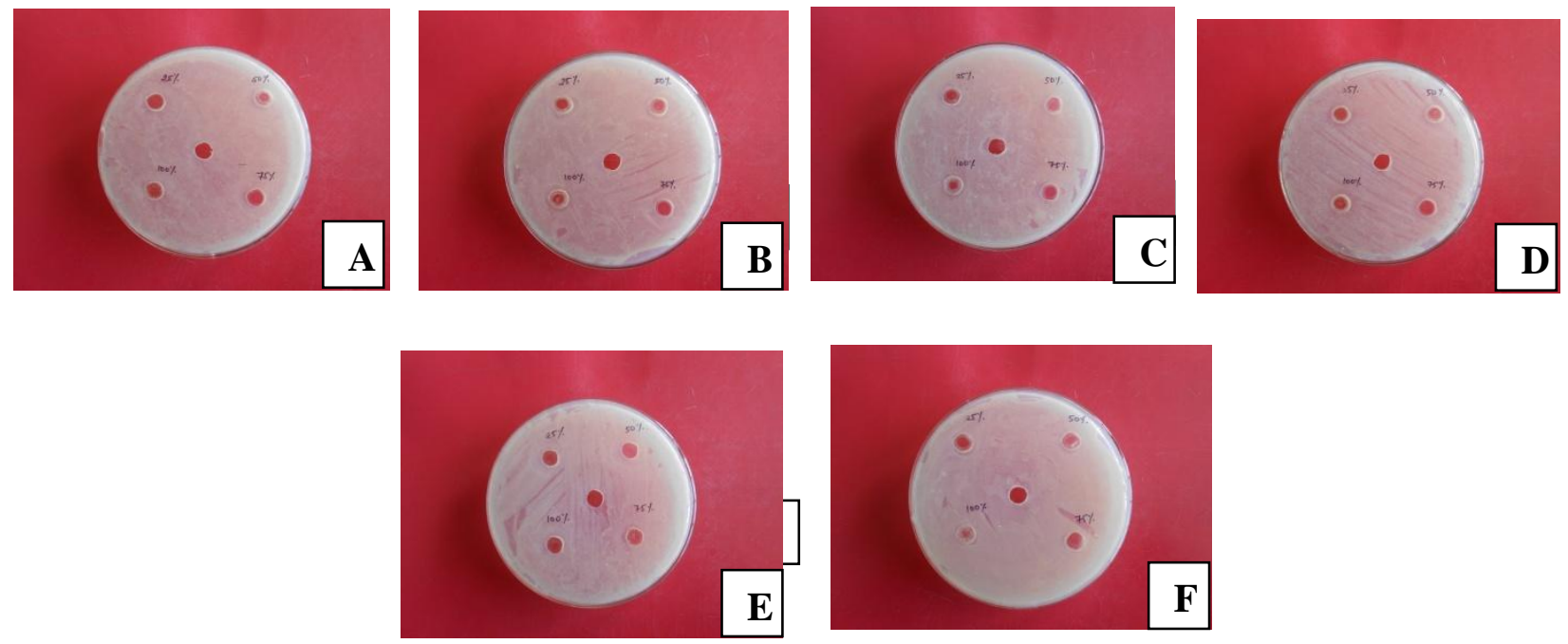

The screening of plant extracts for antimicrobial activity has shown that higher plants are potential source of novel antibiotic prototype (Afolayen, 2003). The present investigation is in agreement with Ballal et al. (2001) as they found that alcoholic and aqueous stem bark extracts of H. antidysentrica were sensitive to strains of clinical pathogens. Bark extracts of Wrightia tinctoria and Wrightia arborea (Apocynaceae) showed antibacterial activity against eight tested bacterial strains (Khyade and Vaikos, 2011). Mahato et al. (2013) found that bark, seed and callus extracts of $H$. antidysenterica possess potential antibacterial activity against $S$. aureus,

Salmonella typhimurium and E. coli. Farrukh et al. (2006) found that ethanolic bark extracts of $H$. antidysenterica showed inhibition zone against the anti-methicillin resistant Staphylococcus aureus (MRSA). Mule et al. (2013) found that $H$. antidysenterica stem bark extracts have antibacterial activity against E. coli, Salmonella typhi, and S. aureus.

In conclusion, growth of almost all the tested bacteria was inhibited by both methanol and acetone extracts of leaves and bark of $H$. antidysenterica but methanolic extract of leaves as well as bark showed higher range of inhibition diameter in 
comparison to acetone extracts. So, it is hoped that this study would lead to the establishment of some compounds that could be used to develop effective and more potent antibacterial drugs of natural origin against human pathogenic bacterial strains.

\section{Acknowledgement}

Thanks are due to the Chairman, Department of Biosciences, H.P. University, Shimla for providing necessary laboratory facilities. Financial assistance provided by UGC, (F1-17. RGNF-34443, SA-3) New Delhi is also highly acknowledged.

\section{References}

Afolayan, A.J. 2003. Extracts from the shoots of Arctotis artotoides inhibit the growth of bacteria and fungi. Pharm. Biol., 41: 2225.

Ballal, M., Srujan, D., Bhat, K.K., Shirwaikar, A., Shivananda, P.G. 2001. Antibacterial activity of Holarrhena antidysenterica [kurchi] against the enteric pathogens. Ind. J. Pharmacol., 33: 392-393.

Farrukh, A., Iqbal, A., Mohd, O. 2006. Evaluation of antimethicillin-resistant Staphylococcus aureus (MRSA) activity and synergy of some bioactive plant extracts. Biotech. J., 1: 1093-1102.

Farnsworth, N.R. 1994. The role of medicinal plants in drug development. In: Krogsgaard-Larsen, S., BroggerChristensen, S. and Kofod, H. (Eds.), Natural Products and Drug Development. Munksgaard, Copenhagen.

Hemashenpagam, N., Selvaraj T. 2010. Antibacterial potential of different extracts of Solanum xanthocarpum Chard and Wendt. Pl. Arch., 1: 387-390.
Jonathan, S.G., Fasidi, I.O. 2003. Antibacterial activities of Nigerian edible macro fungiLycoperdon pusilum (Bat.Ex.) and Lycoperdon giganteus (Pers.). Afr. J. Biomed. Res., 6: 85-90.

Khyade, M.S., Vaikos, N.P. 2011. Comparative phytochemical and antibacterial studies on the bark of Wrightia tinctoria and Wrightia arborea. Int. J. Pharma. Bio Sci., 2:171181.

Kirtikar, K.R., Basu, B.D. 1984. Indian Medicinal plants. Bishen Singh Mahendra Pal Singh, Dehradun, India. 2: 1570-1572.

Lewis, W.H., Elvin-Lewis, M.P. 1995. Medicinal plants as sources of new therapeutics. Ann. Mo. Bot. Gard., 82: 1624.

Mahato, S., Mehta, A., Roy, S. 2013. Studies on antibacterial effects of bark, seed and callus extracts of Holarrhena antidysenterica Wall. The Bioscan., 8(2): 717-721.

Mule, G.D., Waghode, S.M., Garode, A.M. 2013. Antibacterial activity of stem bark of Holarrhena antidysenterica Wall against human pathogenic bacteria. Int. J. Bioassay, 2(5): 817-818.

Nair, R., Chanda, S. 2006. Activity of some medicinal plants against certain pathogenic bacterial strains. Ind. J. Pharm., 38: 142144.

Prumal, S.R., Ignacimuthu, S. 2000. Antibacterial activity of some folklore medicinal plants used by tribals in Western Ghats of India. J. Ethnopharmacol., 69: 63-71.

Rastogi, R.P., Mehrotra, B.N. 2002. Glossary of Indian Medicinal Plants. National Institute of science communication, New Delhi, India.

Saranraj, P., Sivasakthi, S. 2014. Medicinal Plants and its Antimicrobial Properties: A Review. Global J. Pharmacol., 8(3): 316327.

\section{How to cite this article:}

Preeti Kaundal and Anand Sagar. Antibacterial Screening of Leaf and Bark extracts of Holarrhena antidysenterica (L.) Wall. Int.J.Curr.Microbiol.App.Sci. 5(4): 237-243.

doi: http://dx.doi.org/10.20546/ijcmas.2016.504.029 